\title{
Exploitation of Documented Historical Floods for Achieving Better Flood Defense
}

\author{
Slobodan Kolaković, ${ }^{1}$ Julius Fabian, ${ }^{2}$ Sándor Kovács, ${ }^{3}$ \\ Ljubomir Budinski, ${ }^{1}$ and Matija Stipić ${ }^{1}$ \\ ${ }^{1}$ Department of Civil Engineering, Faculty of Technical Sciences, University of Novi Sad, Trg Dositeja Obradovica 6, \\ 21000 Novi Sad, Serbia \\ ${ }^{2}$ Department of Hydraulic, Water Resources and Environmental Engineering, Faculty of Civil Engineering Subotica, \\ University of Novi Sad, Kozaracka 2/a, 24000 Subotica, Serbia \\ ${ }^{3}$ Central Tisza Regional Directorate of Water Management, Boldog Sandor Istvan korut 4, Szolnok 5000, Hungary
}

Correspondence should be addressed to Julius Fabian; julius@gf.uns.ac.rs

Received 2 October 2015; Revised 30 January 2016; Accepted 1 February 2016

Academic Editor: Ozgur Kisi

Copyright (C) 2016 Slobodan Kolaković et al. This is an open access article distributed under the Creative Commons Attribution License, which permits unrestricted use, distribution, and reproduction in any medium, provided the original work is properly cited.

\begin{abstract}
Establishing Base Flood Elevation for a stream network corresponding to a big catchment is feasible by interdisciplinary approach, involving stochastic hydrology, river hydraulics, and computer aided simulations. A numerical model calibrated by historical floods has been exploited in this study. The short presentation of the catchment of the Tisza River in this paper is followed by the overview of historical floods which hit the region in the documented period of 130 years. Several well documented historical floods provided opportunity for the calibration of the chosen numerical model. Once established, the model could be used for investigation of different extreme flood scenarios and to establish the Base Flood Elevation. The calibration has shown that the coefficient of friction in case of the Tisza River is dependent both on the actual water level and on the preceding flood events. The effect of flood plain maintenance as well as the activation of six potential detention ponds on flood mitigation has been examined. Furthermore, the expected maximum water levels have also been determined for the case if the ever observed biggest 1888 flood hit the region again. The investigated cases of flood superposition highlighted the impact of tributary Maros on flood mitigation along the Tisza River.
\end{abstract}

\section{Introduction}

According to the concept of flood defense relying on the Base Flood Elevation corresponding to the design flood of a given recurrence interval, the expected maximum water levels need to be determined all along the river. It is not a clear task, since the BFE depends on many factors, among others on the actual condition of the tributary network in the considered catchment. Producing a suitable solution toola flow analysis numerical model-requires interdisciplinary approach exploiting statistical hydrology, river hydraulics, and computer science. In case of large catchments the numerical model may become complex due to the big number of tributaries involved, all having specific flow conditions [1-5]. High velocities and low discharges are characteristic to the upstream tributaries [1] and low velocities and high discharges are typical to the river sections in lowlands $[4,5]$.
A flow analysis software package known by acronym HEC-RAS has been adopted in this study by the authors. It is capable of accounting for a wide variety of conditions and influences. However, it needs to be calibrated for the conditions of extreme floods which are unique in many aspects $[6,7]$. Not any flood event is suitable for calibration purposes, since all aspects of extreme floods need to be revealed by the chosen floods [8].

Once the model is set up properly, it can be used to simulate different possible flood scenarios having specific chance of occurrence $[2,9]$, imposing certain level of threat to the community. The model produces information regarding maximum water levels along the reaches, corresponding to the modeled extreme flood event. Exhaustive investigation of scenarios corresponding to well-documented historical floods finds out the expected highest peak water levels, in consequence, the safest solution. This approach-applicable 
to any catchment-is presented in this paper through the example of the Tisza River.

The catchment of the Tisza River is chosen by reason, since due to its size and characteristics it exhibits a number of special conditions which might influence the expected maximum water levels (inhomogeneous hydrological conditions over the subcatchments, intensive change of the river bed due to erosion/deposition, superposition of flood waves coming from tributaries, and so on). The catchment of the Tisza River having area of $157.200 \mathrm{~km}^{2}$ is considered to be the most important tributary of the Danube River. Approximately $30 \%$ of the total catchment area of the Tisza River spreads in the Hungarian lowlands, while the rest $70 \%$ is in the territory of Slovakia, Ukraine, Romania, and Serbia. In terms of elevations, $46 \%$ of the catchment is below $200 \mathrm{MSL}$ (related to the Baltic Sea), 34\% is between 200 and $500 \mathrm{MSL}$, and the remaining $20 \%$ is located between 500 and $1600 \mathrm{MSL}$. The annual drainage exceeds $1500 \mathrm{~mm}$ in the highest parts of the catchment, while it remains below $28 \mathrm{~mm}$ in the lowlands, producing discharge from $50 \mathrm{l} / \mathrm{s}$ to $0.8 \mathrm{l} / \mathrm{s}$ per square $\mathrm{km}$ of the catchment.

The shape of the catchment is almost circular having diameter of $460 \mathrm{~km}$ in the north-south direction and $520 \mathrm{~km}$ in the east-west direction. Extreme climate conditions over the catchment, the relative contribution of individual tributaries (Upper-Tisza, Tur, Szamos, Kraszna, Lonyai Canal, Bodrog, Sajo-Hernad, Eger-Creek, Lasko-Creek, Zagyva, Koros, Maros, Aranka, and Bega) to the total flow of the Tisza River, extremely low bed slope of the section stretching in the Hungarian lowlands, significant amount of sediment carried by the river, and the existing water training works altogether make the Tisza River one of the most variegated rivers in the region, producing extreme floods as well as extreme low flow periods. As a result, 1919, 1941, 1970, 1980, and 1998 were plentiful in water. Contrarily, 1921, 1943, 1961, 1973, 1990, and 1994 were short in water.

There is no other river in Europe which encountered so radical reduction in length by regulation works (from $1398.9 \mathrm{~km}$ to $945.8 \mathrm{~km}$ ). The flow is restricted by embankments almost along its whole length, while three dams built in the recent five decades radically changed the mid- and low-flow regimes. On the one hand, the mentioned regulation works along with the deforestation of the catchment increased the runoff and the peak flood discharges. On the other hand, the increased water demand of the industry and of the agriculture further reduced the low discharges during the dry periods.

For the ongoing radical anthropogenic impacts on the flow regime of the river during the last century and due to the risks involved, this study targets extreme flood events. Past floods can be employed for calibration of a suitable numerical model, used later as a tool for predicting the possible outcome of extreme flood scenarios. This opportunity has been investigated by this study.

\section{Methods and Materials}

2.1. Overview of Historical Floods in the Catchment of the Tisza River. The basic parameters of a flood wave are its volume, peak discharge, and duration. Actually, the hydrograph of the flood wave provides the most information. The peak water level caused by the flood wave-depending on the location and time of interest-is rather consequence than basic parameter of the flood. Table 1 shows the peak water levels of the observed historical floods at four river stations along the Tisza River together with the corresponding intermittent periods.

The 1885 flood is of exceptional importance, not only for its volume, but for the fact it was the last extreme flood before regulation works along the Tisza River commenced. Meander cutoffs and restriction of the river by levees increased the peaks of successive floods. The 1879 flood destroyed more than $93 \%$ of buildings in Szeged and claimed 151 lives. The flood peak in 1888 was the absolute maximum until 1919, while it is still not overpassed at Dombrad. Following the accomplishment of the regulation works, the 1895 floodeven though moderate compared to the earlier ones-caused significant damage. The 1919 flood was distinctive in sense of threatening public security all along the river. Following the 1932 flood the practice of watercourse-restricting measures in flood control was abandoned. The flood in 1940 was associated with ice. In 1941 three floods occurred, one in January-February, the second in March-April, and the third in September-October. More moderate floods were characteristics of 1942. The following significant flood happened in 1964. The biggest flood ever-in terms of both peak discharge and duration-happened in 1970. It lasted 125 days, 65 settlements have been evacuated, and 43000 people have been engaged in flood defense. The following flood in 1979 produced peak level at Szolnok just $5 \mathrm{~cm}$ below the earlier maximum. In 1991 and in 2000 the earlier highest level (detected in 1970) was exceeded by $1.5 \mathrm{~m}$, an increment not experienced for about a century. Proceeded by an early spring flood significant flood happened in fall 1998. The flood in 1999 was triggered by snowmelt and by the changes in the river bed during the last three decades. This flood was extraordinary in terms of peak level, velocity, and duration, exceeding the corresponding values of the 1970 flood. Leaking of dikes in 1100 locations was discovered (and treated), intervention in cases of 127 boils was needed, and creeping of embankment face in 26 cases has been registered. 2001 was not easier at all. 2005 and 2006 produced a flood lasting through the winter to the spring, supported by snowmelt and intensive rainfall in April. The 2010 flood was triggered by extraordinary rains, bringing six times more precipitation than average to the watershed.

Not only are the main parameters of the flood events informative; looking at the details of their genesis is even more instructive. In case of the Tisza River, in general, floods occur mostly at spring in the period of MarchMay. Floods are least probable in September. In addition to the extreme meteorological conditions, excessive floods are triggered by late snowmelts accompanied with heavy spring rainfalls, or by coincidence of tributary peak discharges, and by restricting the flood plain by embankments.

2.2. The Modeled Stream Network of the Tisza River. The modeled section of the Tisza River between Kiskore and Titel is $403 \mathrm{~km}$ long, including 7 tributaries and 13 reaches. 


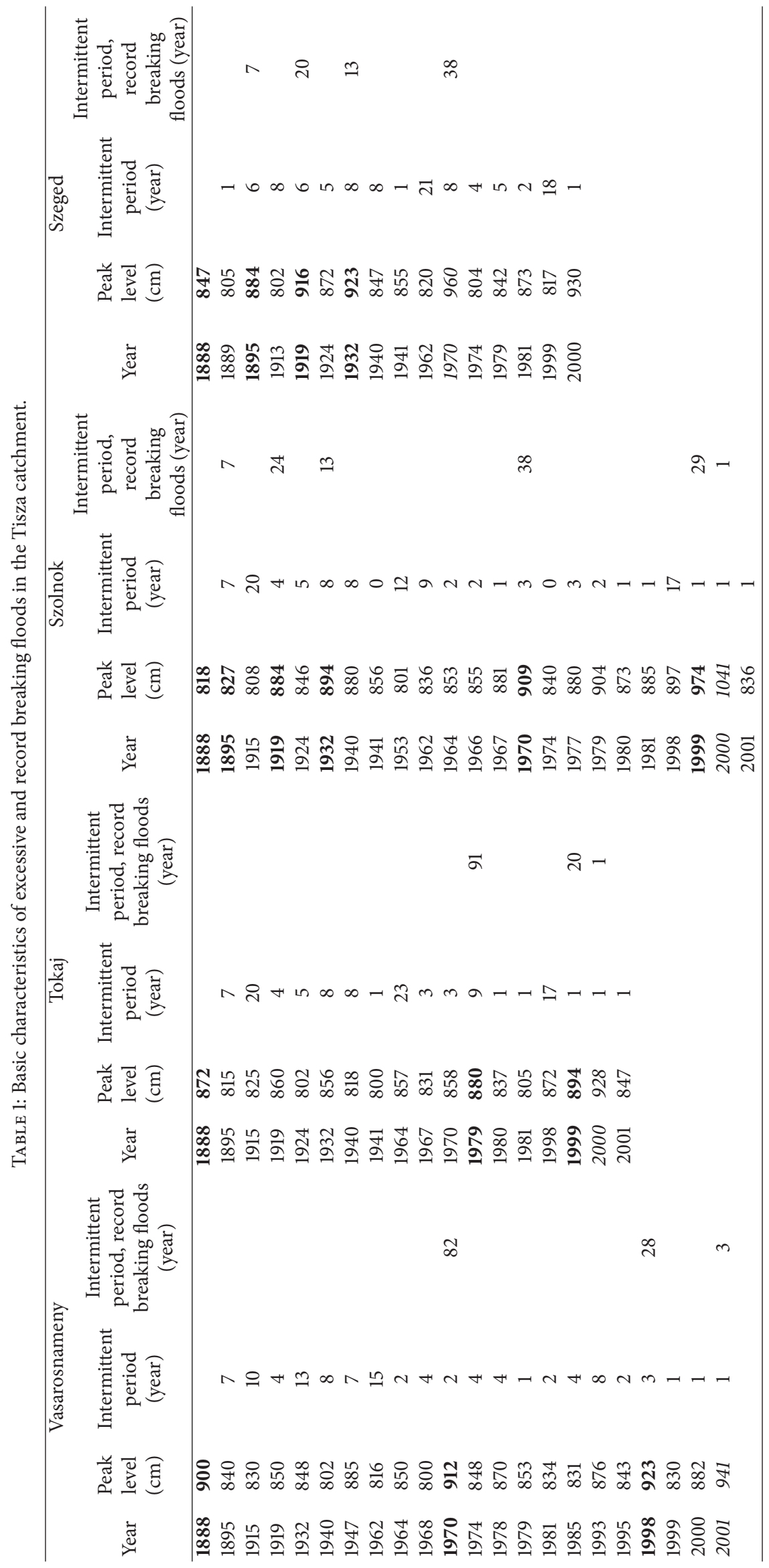




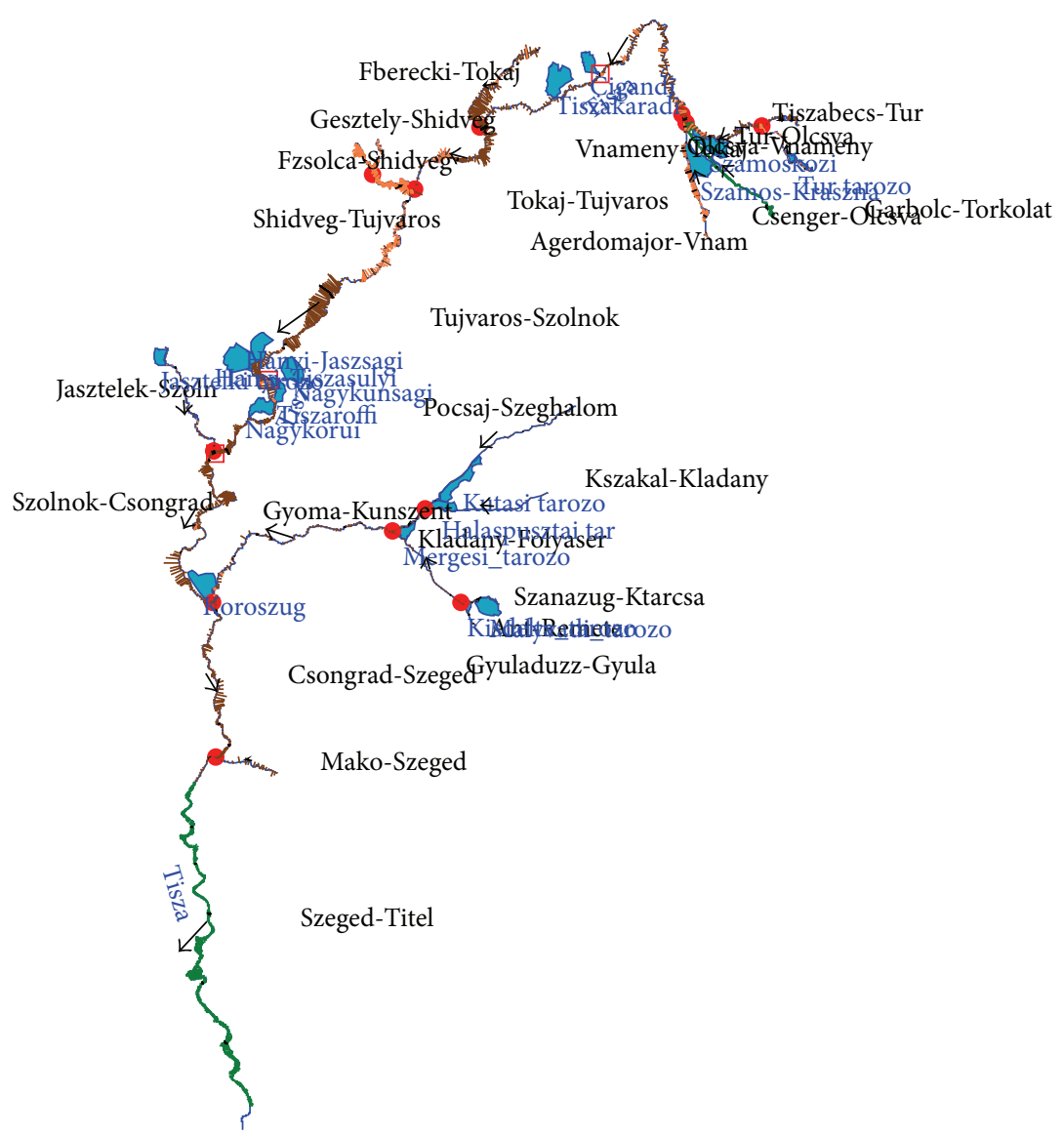

FIgURE 1: Stream network of the Tisza River.

The total length of the streams involved exceeds $762 \mathrm{~km}$. Bathymetry is defined by around 1200 cross sections. 62 bridges, 1 inline structure, 5 lateral structures, and 12 already existing flood reducing detention ponds are incorporated into the model, Figure 1. Eight out of twelve detention ponds have gate controlled in/outlets, particularly:

(i) Five on the Tisza River: the Beregi, Cigandi, Nagykunsagi, Hanyi-Tiszasulyi, and Tiszaroffi.

(ii) One on the Szamos: the Szamos-Krasznai.

(iii) One on the Fekete-Koros: the Malyvadi.

(iv) One in the junction of the Fekete Koros and the FeherKoros: the Kisdelta detention pond.

2.3. The HEC-RAS Model. Computer aided analysis of welldocumented, reliable, historical flood data is the most instructive and straightforward way of learning about floods and predicting the most likely consequences [6]. The River Analysis System software-known by acronym as HECRAS-developed in the Hydrologic Engineering Center by the US Army Corps of Engineers has been adopted for this study by the authors $[10,11]$. The HEC-RAS software is capable of simulating $1 \mathrm{D}$ steady and unsteady flow in a system of natural and constructed channels, producing as a result the corresponding water surface profiles and the related data.
The general principles of modeling unsteady flow in systems of open channels in the HEC-RAS environment are given in $[3,5,12,13]$. Unsteady flow routing using HECRAS is provided by numerical solution of the continuity and momentum equations. The derivation of the governing equations is presented in [10] by Liggett. The most successful and accepted procedure for solving the one-dimensional unsteady flow equations is the four-point implicit scheme, also known as the box scheme. The software package can handle hydraulic structures like bridges, barrages, culverts, overflow weirs, floodgates, bottom stages, bottom sills, side overflows and gates, static reservoirs, pump stations, and water intakes. Example of application in a complex flood control project is given by [7]. Extended description of the software is given in [11].

2.4. Calibration and Verification of the Model. Calibration is feasible by adjusting the global parameters of the model-in most of the cases Manning's coefficient of friction, eventually the loss coefficients of expansion/contraction $[2,8,9]-$ providing successful reproduction of a well-documented past real flood event. Initial values of friction coefficient were estimated by digital aerial orthophotography and in situ surveys, while the final values - separately for the main channel and for the flood plain-were determined by calibration using historical flow data. Calibration is a straightforward procedure in cases of rather frequent floods. However, detailed 
TABLE 2: Manning's coefficient of friction.

\begin{tabular}{lcc}
\hline Year & Main channel & Flood plain \\
\hline 1979 & 0,0286 & 0,0309 \\
\hline 1998 & 0,0285 & 0,0420 \\
\hline
\end{tabular}

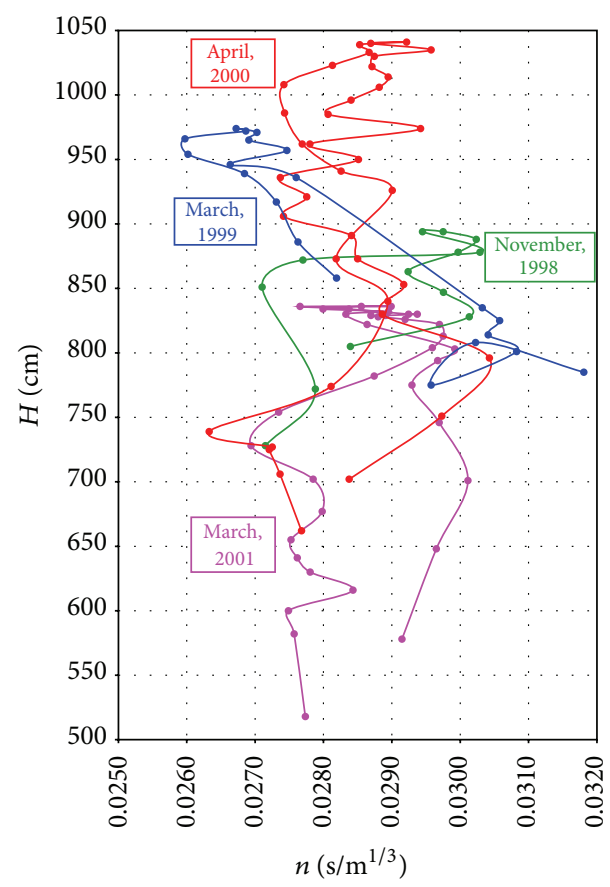

FIGURE 2: Variation of Manning's coefficient of friction by water level, main bed at Szolnok.

data for extreme floods are seldom available, making them valued.

Flow measurements during flood recession in 1998 were carried out from bridges and boats. Comparison of the 1998 measurement with an earlier one in 1979 produced results shown in Table 2.

The data show almost unchanged characteristics in case of the main channel; however, flow conditions in the flood plain are significantly deteriorated during the corresponding two decades causing reduction in flow capacity up to $300 \mathrm{~m}^{3} / \mathrm{s}$.

Successive measurements in 1998, 1999, 2000, and 2001 produced results shown in Figures 2 and 3 for the main bed and for the flood plain, respectively. The graphs reveal change in friction depending on the time of observation and on the actual water level. Variation of friction coefficient from 0.026 to 0.032 is observed in the main bed and from 0.025 to 0.048 in the flood plain. Increase in friction is due to the development of plant cover in the watercourse. Passing a flood wave often triggers decrease in friction as cutting a passage through an upsilted river section cleans the waterway.

Calibration of the Tisza River model was achieved making use of almost 50 time series comprising of hourly detected water levels at standard measuring posts, and water level readings of dam keepers. In the calibration process default values, 0.3 and 0.1 , have been adopted for the expansion and contraction coefficients, respectively. Manning's coefficients

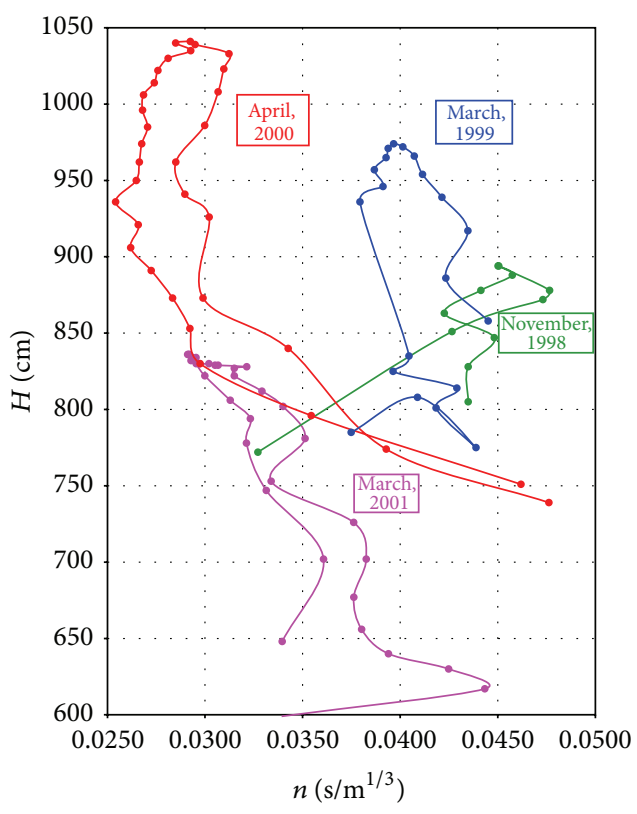

FIGURE 3: Variation of Manning's coefficient of friction by water level, flood plain at Szolnok.

for the main channel and for the flood plain were determined separately in each cross section. Figures 2 and 3 demonstrate an attempt to establish water level dependant Manning's coefficient; however, it could be achieved for short river sections only.

The blue line in Figure 4 represents the calculated peak water levels, while the red dots are the observed maximum water levels corresponding to the 2006 flood. The maximum difference between the calculated and observed water levels in the river section between Tiszabecs and Titel was $5 \mathrm{~cm}$, which may be considered as very good agreement.

\section{Application of the Model}

Along the Hungarian section of the Tisza River, peak flow levels have overpassed the Base Flood Elevation during the 2000 flood, at some locations even by $80 \mathrm{~cm}$. Flood protection by endless increasing in the height of the dikes is unfeasible. Alternative solution is reaching the goal by flood plain interventions and by employing detention storages along the river to reduce the peak water levels. Six detention pondsthe Szamos-Krasznakoz, Cigand, Hany-Tiszasuly, Nagykoru, Nagykunsag, and Tiszaroff-have been assigned for this purpose. The first case study is aimed at checking the expected efficiency of flood plain maintenance and activation of detention storages in flood defense.

The second case study investigates if the 1888 extreme flood applied to the current condition of the watercourse could pass nowadays without causing disaster.

At last, flood superposition scenarios have been studied in the third case study by the means of the calibrated model.

3.1. Flood Plain Maintenance, Detention Storages. The influence of flood plain maintenance and the impact of detention 


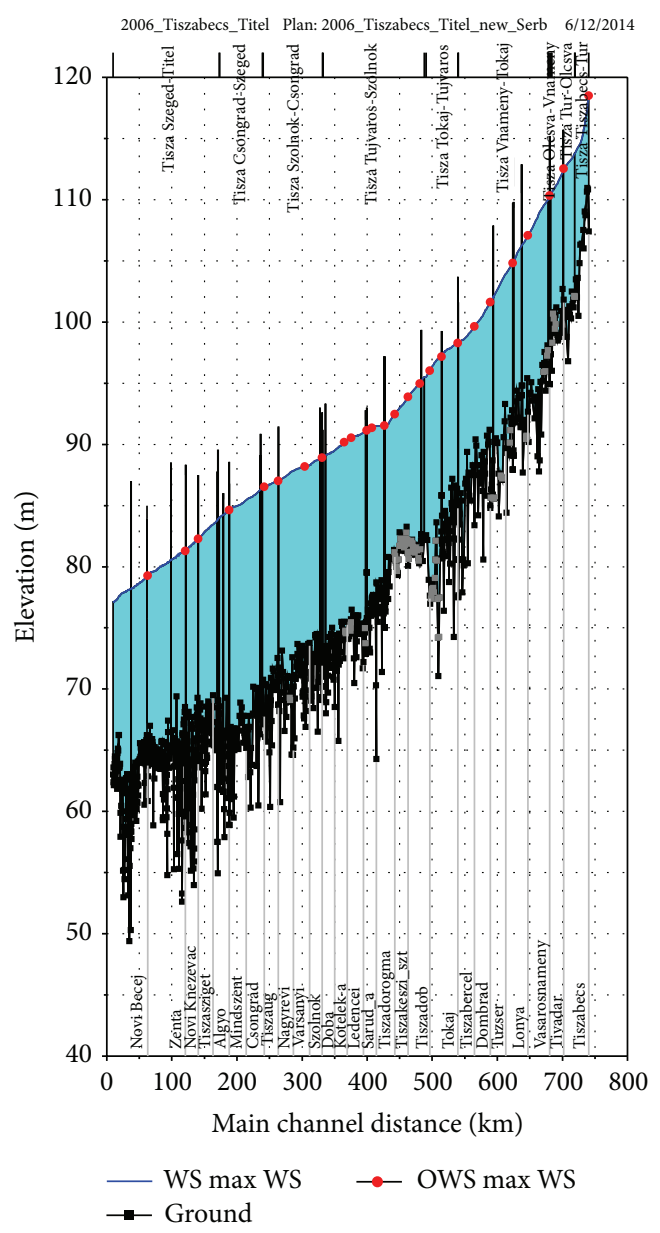

FIGURE 4: Verification of the calibrated parameters against the observed water levels of the 2006 flood.

ponds on flood mitigation have been investigated by the calibrated model: Cases

(a) with flood plain maintenance, without detention ponds activated,

(b) with detention ponds activated, without flood plain maintenance,

(c) with flood plain maintenance, with detention ponds activated

have been considered. The data of the 2000 flood have been exploited in this study for good reason; it was record breaking in terms of maximum water levels even at five locations, Tokaj, Tiszafured, Tiszabo, Szolnok, and Csongrad, Table 3.

The results are shown in Figure 5, where $\Delta z(\mathrm{~cm})$ denotes water level difference due to a particular intervention, compared to the peak water levels expected for the current condition of the river bed; $x$ is river station $(\mathrm{km})$. The light green line represents case (a), the blue line corresponds to case (b), and the dark green line shows the joint effect of both interventions, case (c). The increase of peak water levels in the downstream section $(x<220 \mathrm{~km})$ caused by flood plain maintenance is successfully compensated by the effect of detention ponds. With both measures applied, the maximum water levels could be reduced up to $160 \mathrm{~cm}$.

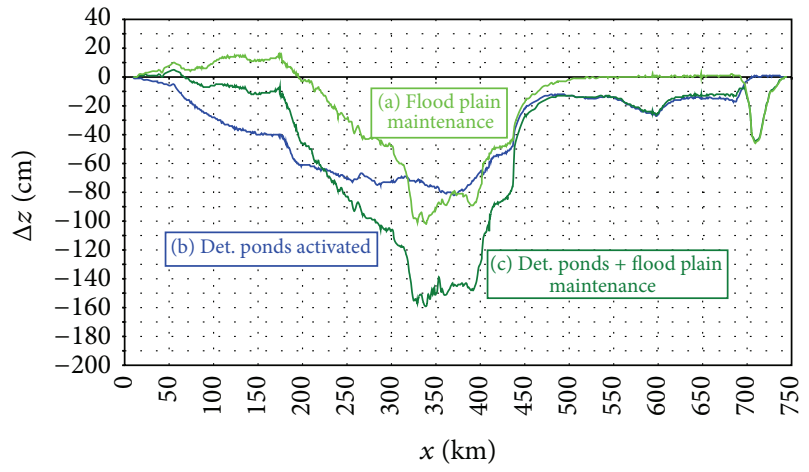

FIGURE 5: Calculated effects of flood plain maintenance and activation of detention ponds on the peak water levels in case of the 2000 flood.

Further improvement in terms of maximum water levels might be achieved using more sophisticated techniques in activation of the eight gate-controlled detention ponds [14]. Calculation results are similar for the 2006 flood as well.

3.2. Application of the 1888 Flood to the Current Condition of the Watercourse. The 1888 flood was so severe that the corresponding maximum water level detected at Dombrad 
TABLE 3: Overview of peak flood levels.

\begin{tabular}{|c|c|c|c|c|c|c|c|c|c|c|}
\hline Year & $\begin{array}{l}\text { TIVA- } \\
\text { DAR }\end{array}$ & $\begin{array}{l}\text { VASAROS- } \\
\text { NAMENY }\end{array}$ & ZAHONY & DOMBRAD & TOKAJ & $\begin{array}{l}\text { TISZA- } \\
\text { FURED }\end{array}$ & TISZABO & SZOLNOK & $\begin{array}{c}\text { CSONG- } \\
\text { RAD }\end{array}$ & SZEGED \\
\hline 1888 & 753 & 900 & 751 & 890 & 872 & 742 & & 818 & 834 & 847 \\
\hline 1895 & & & & & & & 866 & 827 & 867 & 884 \\
\hline 1912 & 790 & & & & & & & & & \\
\hline 1919 & & & & & & & 919 & 882 & 929 & 916 \\
\hline \multicolumn{11}{|l|}{1925} \\
\hline 1932 & & & & & & 750 & 921 & 894 & & 923 \\
\hline \multicolumn{11}{|l|}{1933} \\
\hline 1947 & 848 & & & & & & & & & \\
\hline 1967 & & & & & & 765 & & & & \\
\hline 1970 & 865 & 912 & & & & 773 & 935 & 909 & 935 & 961 \\
\hline 1979 & & & & & 880 & 788 & 949 & & & \\
\hline 1998 & 964 & 923 & & & & & & & & \\
\hline 1999 & & & & & 894 & 835 & 1023 & 974 & & \\
\hline 2000 & & & & & 928 & 881 & 1080 & 1041 & 994 & \\
\hline 2001 & 1014 & 941 & 758 & & & & & & & \\
\hline 2006 & & & & & & & & & 1033 & 1009 \\
\hline $\begin{array}{l}\text { Number of } \\
\text { record- } \\
\text { breaking } \\
\text { peaks } \\
\text { following the } \\
1888 \text { flood } \\
\end{array}$ & 6 & 4 & 2 & 1 & 4 & 7 & 7 & 7 & 6 & 6 \\
\hline
\end{tabular}

is still not overpassed. In addition, it has occurred in case of watercourse unrestricted by dikes. Even more, extreme water levels over $800 \mathrm{~cm}$ lasted more than 14 days in the Vasarosnameny region. For the sake of comparison it is interesting to note that none of the recent floods $(1998,2001)$ exhibited peak water levels lasting longer than 3.5 days.

This simulation is meant to check if the 1888 flood could pass nowadays without causing trouble. The observed stage hydrograph of the 1888 flood has been set as upstream boundary condition. Stage hydrograph of the 2000 flood has been applied to the outlets of the tributaries and to the most downstream cross section of the Tisza River. The results of simulation compared to the consequences of the 2000 flood are shown in Figure 6. It clearly demonstrates that if the 1888 flood happened nowadays, it would have caused up to $80 \mathrm{~cm}$ higher peak levels than the 2000 flood did. Between Tiszalok and Tiszaug peak water levels would over pass the BFE up to $180 \mathrm{~cm}$ and they would last over 25 days! It is interesting to notice that, with flood plain maintenance carried out and all planned detention storages accomplished, most of the Hungarian section of the Tisza River could pass the 1888 extreme historical flood.

\section{Superposition of Floods}

A particular flood event on the Tisza River is significantly influenced by the

(i) intensity and duration of floods corresponding to each tributary,

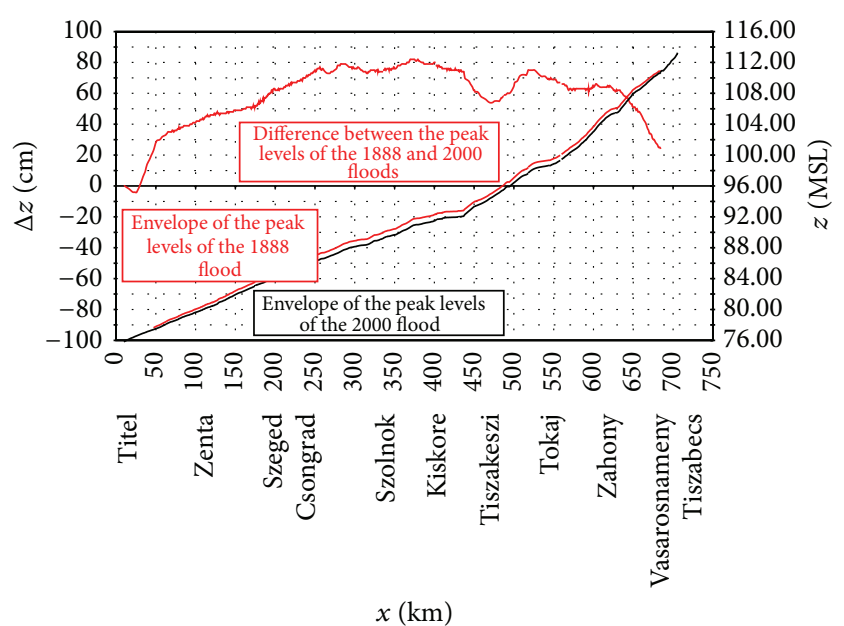

FIgURE 6: The expected maximum water levels of the 1888 flood calculated with the current condition of the watercourse, compared to the observed maximum water levels of the 2000 flood.

(ii) timing of flood waves of tributaries in relation to the flood wave of the Tisza River.

Wide variety of flood wave superposition is possible producing different outcome in terms of peak levels and peak discharges. Of course, each of these specific combinations has its own chance of occurrence. Some of them-having 


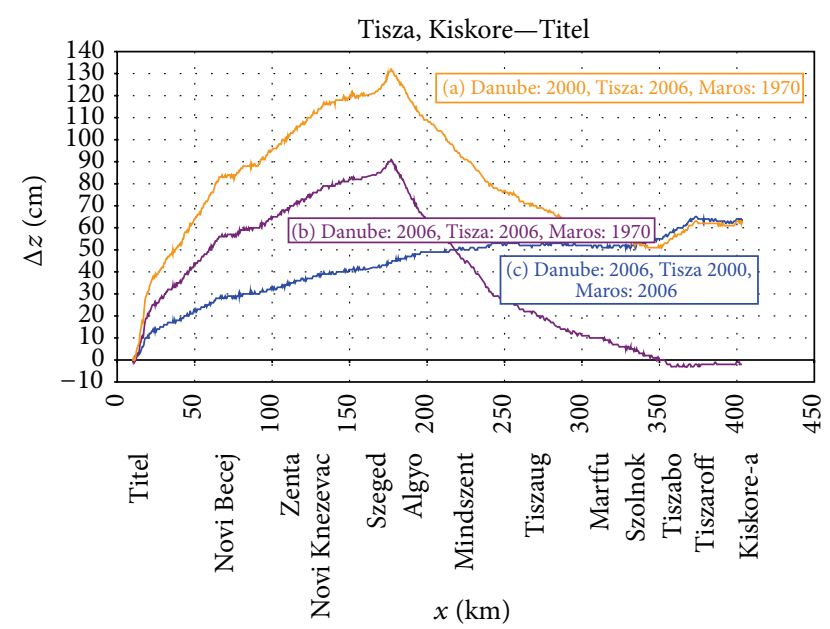

Figure 7: The calculated peak water levels for different flood superposition scenarios.

higher practical significance in planning flood defense-are investigated described as follows:

(a) Orange curve in Figure 7: the 2000 year flood is applied to the Danube, the 2006 flood to the Tisza, and the 1970 flood to the Maros.

(b) Purple curve in Figure 7: The 2006 year flood is applied to the Danube and to the Tisza, and the 1970 flood to the Maros.

(c) Blue curve in Figure 7: The 2006 year flood is applied to the Danube, the 2000 flood to the Tisza, and the 2006 flow hydrograph to the Maros.

In Figure 7 the envelope of peak water levels corresponding to the 2006 flood is the reference to which the levels of the investigated cases are compared.

Since the 2006 hydrograph of the Maros was not excessive, peaking at Szeged did not happen, case (c). As the 1970 flood of the Maros was extreme if it happened again, it would have caused excessive peak water levels, at Szeged, up to $130 \mathrm{~cm}$ higher than the reference peak level produced by the 2006 flood, cases (a) and (b).

This example highlights the need for stochastic approach in flood analysis in order to get insight into the probability of extreme flood scenarios. In combination with a well calibrated, reliable model, powerful tool in search for the most effective solutions in flood defense could be established.

\section{Conclusions}

Flood routing is a multidisciplinary complex task. In addition, conditions in a specific catchment are continuously changing partly due to anthropological influences, partly due to natural processes. Numerical models seem to be the only tool which can tackle the problem. If they are to be used for simulation of extreme floods, their calibration with well documented, historical flood data is inevitable. This approach ensures that all particular conditions specific to extreme floods (stochastic character of the event, significant flood plain flow, and inundation storage) reveal themselves.

Modeling different scenarios is currently the most suitable approach to investigate the effects of different flood control approaches; in this paper the influence of flood plain maintenance and exploitation of detention storages have been investigated with good results. Possible superposition of different flood-augmenting influences requires probabilistic approach to flood analysis. Therefore, numerical models combined with statistical hydrology seem to be the most suitable tool for flood prognosis.

The Base Flood Elevation corresponding to the design flood of a given recurrence interval may not be once and forever established, since the bathymetry of the reaches is continuously changing due to the erosion/deposition processes. In addition, seasonal variations are caused by cyclical changes in vegetation. Furthermore, hydrological events are of stochastic character. For that, a design flood of a chosen probability may come about in huge number of scenarios, each producing particular BFE at the location of interest. Therefore, BFE ensuring identical safety over the whole catchment is achievable by establishing the envelope of maximum BFEs coming from different flood scenarios. The envelope of BFEs is attainable by computer aided simulations only, combined with statistical hydrology or by exploiting data of extreme historical floods.

\section{Conflict of Interests}

The authors declare that there is no conflict of interests regarding the publication of this paper.

\section{Acknowledgments}

This work has been carried out using data provided by the Directorate for Water Management of Lower Tisza District, Szolnok, and by the Directorate for Water Management of Middle Tisza District, Szeged.

\section{References}

[1] K. W. Chau, "Application of the Preissmann scheme on flood propagation in river systems in difficult terrain," in Hydrology in Mountainous Regions. I-Hydrological Measurements; the Water Cycle, IAHS Publications No. 193, IAHS Press, 1990.

[2] S. L. Dingman and K. P. Sharma, "Statistical development and validation of discharge equations for natural channels," Journal of Hydrology, vol. 199, no. 1-2, pp. 13-35, 1997.

[3] R. L. Barkau, UNET One-Dimensional Unsteady Flow through a Full Network of Open Channels User's Manual, US Army Corps of Engineers, Hydrologic Engineering Center, Davis, Calif, USA, 1997.

[4] D. W. Knight and K. Shiono, "Channel and floodplain hydraulics," in Floodplain Processes, M. G. Anderson, D. E. Walling, and P. D. Bates, Eds., John Wiley \& Sons, New York, NY, USA, 1996.

[5] D. W. Knight, K. Shiono, and J. Pirt, "Prediction of depth mean velocity and discharge in natural rivers with overbank flow," in Proceedings of International Conference on Hydraulic and Environmental Modeling of Coastal, Estuarine and River Waters, 
R. A. Falconer, P. Goodwin, and R. G. S. Matthew, Eds., pp. 419428, Gower Technical, University of Bradford, September 1989.

[6] S. Kovács, "Modeling the River Tisza by using one-dimension hydro-dynamic model," in Proceedings of the 3rd International Symposium on Flood Defense, Nijmengen, The Netherlands, May 2005.

[7] S. Kovács and P. Hegedüs, "Using HEC-RAS for complex flood control project," in Proceedings of the FMA Annual Conference, Sacramento, Calif, USA, September 2005.

[8] F. Pappenberger, K. Beven, M. Horritt, and S. Blazkova, "Uncertainty in the calibration of effective roughness parameters in HEC-RAS using inundation and downstream level observations," Journal of Hydrology, vol. 302, no. 1-4, pp. 46-69, 2005.

[9] G. Kuczera and M. Mroczkowski, "Assessment of hydrologic parameter uncertainty and the worth of multiresponse data," Water Resources Research, vol. 34, no. 6, pp. 1481-1489, 1998.

[10] J. A. Liggett, "Basic equations of unsteady flow," in Unsteady Flow in Open Channels, K. Mahmood and V. Yevjevich, Eds., vol. 1, chapter 2, Water Resources Publications, Fort Collins, Colo, USA, 1975.

[11] Haestad Methods, Floodplain Modeling Using HEC-RAS, Haestad Press, Waterbury, CT, USA, 2003.

[12] C. A. J. Fletcher, Computational Techniques for Fluid Dynamics, vol. I, Springer, Berlin, Germany, 1991.

[13] A. Chadwick and J. Morfett, Hydraulics in Civil and Environmental Engineering, Spon, London, UK, 1999.

[14] T. Haktanir, H. Citakoglu, and N. Acanal, "Fifteen-stage operation of gated spillways for flood routing management through artificial reservoirs," Hydrological Sciences Journal, vol. 58, no. 5, pp. 1013-1031, 2013. 

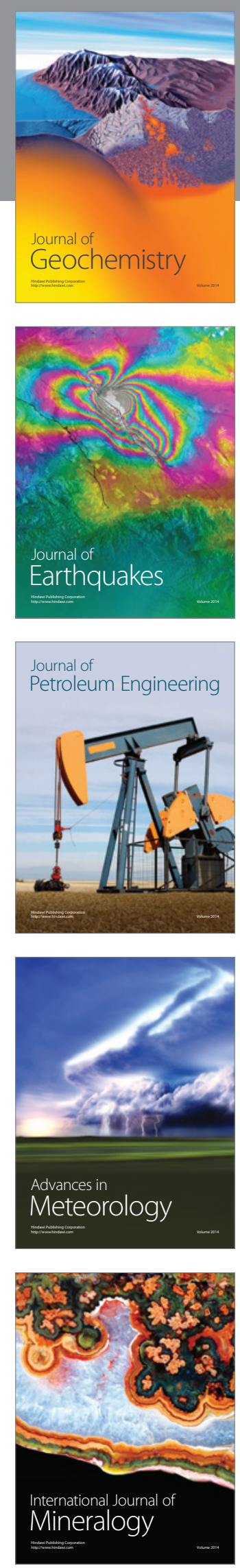
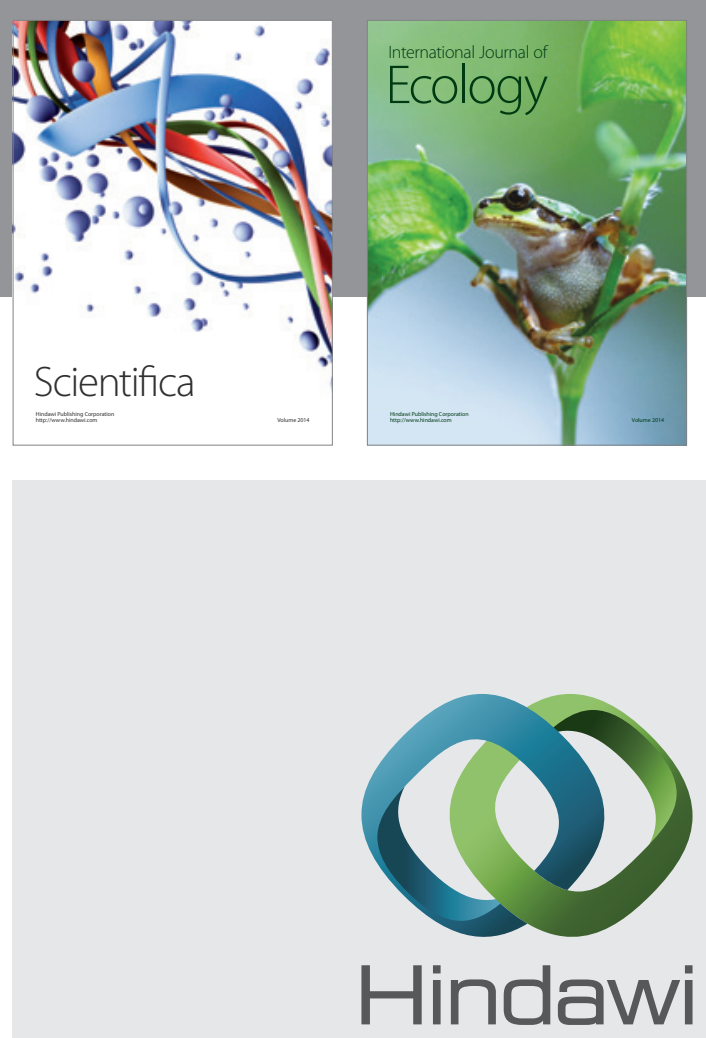

Submit your manuscripts at

http://www.hindawi.com
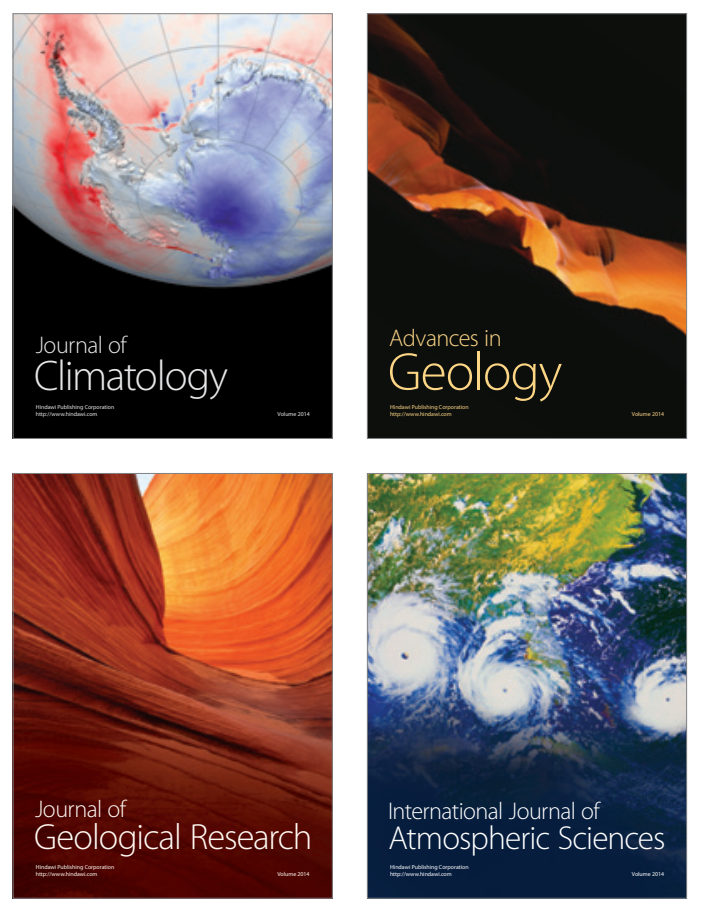

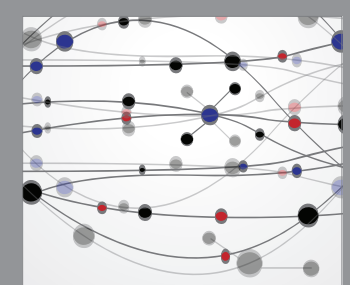

The Scientific

\section{World Journal}
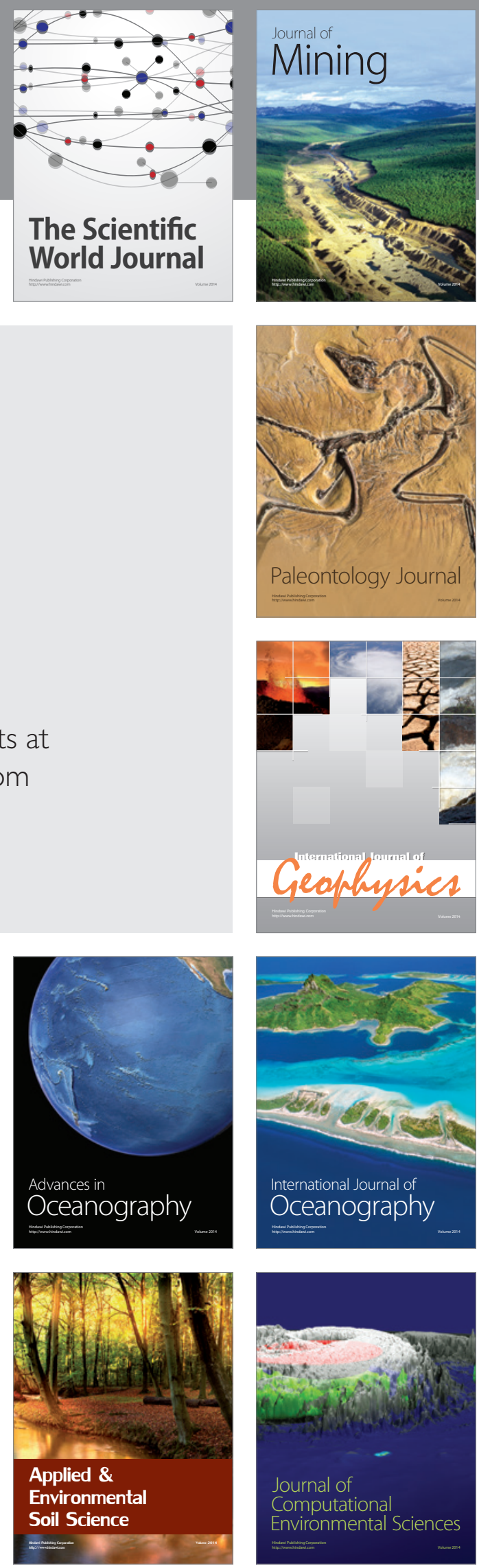